\title{
Resin distribution in axial and circumferential directions of self-wiping co-rotating parallel twin-screw extruder
}

\author{
Kentaro Taki ${ }^{1}$, Shin-ichiro Tanifuji ${ }^{2}$, Masatoshi Ohara ${ }^{3}$, Takemasa Sugiyama ${ }^{4}$, Sho \\ Umemoto $^{5}$, Yuya Obata ${ }^{1}$, Jun-ichi Murata ${ }^{6}$, Isao Tsujimura ${ }^{6}$, and Shin-ichi Kihara ${ }^{4}$ \\ ${ }^{1}$ Kanazawa University \\ ${ }^{2}$ HASL co ltd \\ ${ }^{3}$ Toshiba Machine Co Ltd \\ ${ }^{4}$ Affiliation not available \\ ${ }^{5}$ Kanazawa University Graduate School of Natural Science and Technology \\ ${ }^{6}$ Kaneka Corporation
}

May 5, 2020

\begin{abstract}
A self-wiping co-rotating twin-screw extruder (TSE) is operated in a starved state where the screws are partially filled with resin. Understanding resin distribution on the screw surface is essential for the design, operation, and maintenance of the twin-screw extrusion process. In this study, the circumferential and axial distribution of pressure, temperature, and resin in a TSE are calculated using a novel method combining the mathematical formulation of Hele-Shaw flow, the finite element method, and a newly developed down-wind pressure update scheme. The experimental results were in good agreement with the measured results. This calculation method enables us to visualize, in detail, the resin distribution, pressure, and temperature for the entire axial and circumferential direction over the TSE.
\end{abstract}

\section{Hosted file}

Tanifuji6-maindocument-codeout.docx available at https://authorea.com/users/293979/articles/ 422129-resin-distribution-in-axial-and-circumferential-directions-of-self-wiping-corotating-parallel-twin-screw-extruder 